\title{
ECMO use and mortality in adult patients with cardiogenic shock: a retrospective observational study in U.S. hospitals
}

\author{
Rayan El Sibai ${ }^{1}$, Rana Bachir ${ }^{1}$ and Mazen El Sayed ${ }^{1,2^{*}}$ (D)
}

\begin{abstract}
Background: Extracorporeal membrane oxygenation (ECMO) is increasingly used in resuscitation of critically ill patients with documented improved survival. Few studies describe ECMO use in cardiogenic shock. This study examines ECMO use and identifies variables associated with mortality in patients treated for cardiogenic shock in US hospitals.

Methods: A retrospective observational study of the US Nationwide Emergency Department Sample (NEDS) database of 2013 was conducted. Weighted visits for cardiogenic shock (discharge diagnosis) with ECMO use were included. Collected data was analyzed and variables associated with mortality were identified.

Results: A total of 922 weighted patients with cardiogenic shock and ECMO were included. Mean age was 50.8 years. They were more commonly males $(66.3 \% ; n=658)$. Slightly over half $(51.0 \%, n=506)$ survived to hospital discharge. Mean charges per patient were $\$ 589,610.5$. Mean length of stay was 21.8 days.

Increased mortality was associated with presence of respiratory diseases $(O R=3.83)$, genitourinary diseases $(O R=4.97)$, undergoing an echocardiogram $(\mathrm{OR}=4.63)$, and presenting during seasons other than Fall. Lower mortality was noted in patients with injury and poisoning $(O R=0.47)$, in those who underwent certain vascular procedures $(O R=0.49)$ and those with increasing length of stay $(\mathrm{OR}=0.90)$.

Conclusion: Mortality in patients with cardiogenic shock remains high despite ECMO use. Season of admission (other than Fall) and presence of specific comorbidities (Respiratory and genitourinary diseases) are associated with increased mortality in this population. Familiarity with these variables can help identify patients at higher risk of death and can help improve outcomes further in cardiogenic shock.
\end{abstract}

Keywords: Extracorporeal circulation, Extracorporeal membrane oxygenation, Shock, cardiogenic, Emergency service, hospital, Resuscitation, Critical illness

\section{Background}

Mechanical cardiopulmonary assistance, which is often utilized as an integral part of certain invasive cardiac surgeries, is increasingly used in resuscitation of patients in intensive care settings and emergency departments [1-12]. Prolonged cardiopulmonary assistance is called extracorporeal membrane oxygenation (ECMO) or extracorporeal life support (ECLS) and is a sophisticated and resource-intensive intervention for critically ill patients with cardiac or

\footnotetext{
* Correspondence: melsayed@aub.edu.lb

${ }^{1}$ Department of Emergency Medicine, American University of Beirut Medical Center, P.O. Box - 11-0236, Riad El Solh, Beirut 1107 2020, Lebanon

${ }^{2}$ Emergency Medical Services and Prehospital Care Program, American University of Beirut Medical Center, Beirut, Lebanon
}

respiratory dysfunction $[11,12]$. ECMO and ECLS are often used interchangeably [13].

There are two types of ECMO - veno-venous (VV) and veno-arterial (VA) ECMO - depending on differences in vascular access. During VV ECMO, blood is extracted from the vena cava or right atrium and returned oxygenated to the right atrium. During VA ECMO, blood is extracted from the right atrium and returned oxygenated to the arterial system, most commonly the iliac artery. VA ECMO provides hemodynamic support in addition to respiratory support [11].

Although ECMO use is more commonly described in the pediatric population, ECMO use in adults for cardiac and respiratory indications more recently

(c) The Author(s). 2018 Open Access This article is distributed under the terms of the Creative Commons Attribution 4.0 International License (http://creativecommons.org/licenses/by/4.0/), which permits unrestricted use, distribution, and 
became the largest contributing group in the Extracorporeal Life Support Organization Registry, which was established to improve quality and outcome of ECMO use [4, 12]. ECMO is used for various cardiac or pulmonary diseases including: post-cardiotomy, myocarditis, acute coronary syndrome or refractory cardiac arrest, as a bridge to heart/lung transplant, cardiogenic shock, respiratory failure, trauma/drowning as well as other conditions [14]. In 2015, cardiogenic shock was found to be the most common diagnosis associated with ECLS use in adults with VA ECMO, occurring in $60.7 \%$ of such patients [4]. Cardiogenic shock is a clinical condition of inadequate tissue perfusion due to cardiac dysfunction that is associated with persistent hypotension and end organ damage. Cardiogenic shock often results from myocardial infarction but can also result from other cardiac diseases such as myocarditis, pericarditis, and cardiomyopathy [15].

ECMO use improves survival in patients with cardiac disease with survival rates ranging from 20 to $50 \%$ [1-10]. ECMO also increases 30-day survival rates when used to bridge patients in cardiogenic shock to coronary intervention procedures [16]. Additionally, ECMO improves outcomes in patients with cardiac arrests - mainly survival without neurologic deficit - when added to cardiopulmonary resuscitation (CPR) $[3,17]$.

Contraindications for VA ECMO in cardiac failure do exist and include the following: ethical considerations and patient's will, no bridging goal, severe aortic regurgitation, aortic dissection, severe peripheral artery disease (iliac), left ventricular thrombus (relative contraindication) [18]. Despite several observational and registry studies on ECMO use, few studies describe the extent of ECMO use in patients with cardiogenic shock. This study examines cardiogenic shock presentations that involved ECMO use and identifies variables associated with mortality in this U.S. hospital population sample.

\section{Methods}

\section{Data and materials}

NEDS is a product of Healthcare Cost and Utilization Project (HCUP) under the auspices of the Agency for Healthcare Research and Quality (AHRQ) [19]. It is the largest U.S. all-payer ED database, combining medical and non-clinical data from both national and state sources. Data from this stratified sample is accrued from 945 hospital-owned EDs located across 30 States and the District of Columbia, reflecting approximately $20 \%$ of all hospital-based EDs located in the United States. The following stratification variables were used to weight data per HCUP specifications: U.S. Census region, urban-rural location, ownership, and teaching status of the hospital as well as trauma center designation [20]. This stratified sample of patients is statistically weighted using the above stratification variables to approximate and examine national estimates. Weighting of sample compensates for different probabilities of selection as part of the dataset sample. As per requirements for publishing HCUP data and to safeguard patients' privacy, data on any variable with size less than or equal to 10 are excluded.

\section{Study design and population}

This retrospective study used the 2013 public release dataset of the US Nationwide Emergency Department Sample (NEDS) database. The 2013 NEDS dataset contains information on weighted 134,869,015 ED visits. Patients were included in this study if they met the following criteria: Adult patients (age 18 or older) who presented with cardiogenic shock and underwent ECMO procedure and died in the ED or were admitted to the same hospital during the selected visit.

\section{Data definitions}

The NEDS data elements include: demographic patient information; mechanism, intent, and severity of injury; admission and discharge status; payment source; healthcare expenses and general hospital characteristics. The AHRQ Clinical Classifications Software (CCS) was used to select all patients with cardiogenic shock. CCS is a tool for grouping patient diagnoses and procedures into a convenient number of clinically meaningful categories similar and equivalent to than the International Classification of Diseases (ICD) coding system.

The following CSS codes are specific for cardiogenic shock: CCS 97, CCS 100, CCS 101, CCS 103, CCS 106, CCS 107, CCS 108 [12]. A list of Equivalent ICD-9 CM codes and variable classification is included (See attachment, Additional File 1 which illustrates code and variable classifications). Additionally, the ICD-9 CM procedure code 39.65 was used to gather all patients who underwent ECMO procedure.

Chronic diseases and procedures with frequencies less than $10 \%$ were removed from the analysis and were not displayed results. Injury severity score (ISS) is considered as the gold standard trauma severity score to predict morbidity, increased hospital stay and mortality in trauma patients. An ISS score greater than 15 is historically used as a cutoff value for severe trauma injury [21]. This study used a more conservative cut off value for ISS of $>8$ since very few patients had an ISS score greater than 15. Previous studies have also shown that increasing injury severity (ISS of $>8$ ) is associated with increased hospital stay and ICU admission [22].

AHRQ provides a database and a software tool, called the Chronic Condition Indicator (CCI), that allows for 
the identification of chronic diseases using ICD-9 CM coding. CCI was utilized in this study for the purposes of investigating presence of chronic conditions according to body system categories affected. According to CCI, the definition of a chronic disease is "a medical condition which lasts for twelve months or longer with either one of the following criteria being met: (1) the medical condition restricts self-care, independent living, and social interaction; (2) the medical condition results in the need of ongoing medical intervention."

Additionally, NEDS categorizes ICD-9 CM procedure codes into four broad categories labeled as either major or minor and therapeutic or diagnostic. An ICD-9 CM procedure is classified as "minor if the procedure is a non-operating room procedure and major if the procedure is a valid operating room procedure by the Diagnosis Related Group (DRG) grouper" (an ICD-9 CM grouping system). CCS procedure codes were also used to examine most common procedures other than ECMO.

\section{Statistical analysis}

IBM-SPSS 24 was used to carry out descriptive analysis on the socio-demographic, clinical and hospital characteristics. Mean with associated 95\% confidence intervals (CI) was used for continuous variables, while frequencies, percentages and 95\% CI were used for categorical variables.

The standard statistical methods that treat the data as being emerged from a simple random sampling data were inappropriate for the NEDS survey design and would yield biased estimates, overly-narrow confidence levels and misleading significance tests due to the type I error generated from the biased results. The Rao-Scott chi-square test, a modified version of the Pearson's chi-square test, as well as a general linear model (GLM) for complex sampling (CS) were used to assess the significance of the statistical association of the independent categorical and continuous variables respectively between the two groups (those who survived and those who did not). Logistic regression was conducted to identify significant associations with mortality in ECMO patients with cardiogenic shock. Variables that were significantly different between the two groups when compared by outcome (mortality) were included in the multivariate analysis.

All estimates (means, percentages, odds ratio and confidence intervals) were drawn by complex sampling methods, particularly, CSTABULATE, CSDESCRIPTIVES, CSGLM and CSLOGISTIC to adjust for the NEDS survey design and to ensure the results are accurate. CSTABULATE is a complex sample procedure that produces analysis for categorical variables. CSDESCRIPTIVES and CSGLM are two different complex sample procedures that allow for analysis of continuous variables at the univariate and bivariate levels respectively. Lastly, the Complex Samples Logistic Regression procedure, CSLOGISTIC, performs logistic regression for samples drawn by complex sampling methods.

Complex sampling design of the study resulted in decimal places among sample frequencies. To avoid rounding errors and for the sake of clarity, variables were restored to discrete format by discarding decimals. In addition, a maximal value for total sample frequency was capped at 992 patients. Analysis was verified using HCUPnet, a free on-line query system based on data from HCUP [23]. Lastly, a $p$-value of $<0.05$ was used to indicate statistical significance.

\section{Results}

A total of 8,605,807 weighted adult visits were admitted to the emergency department with cardiogenic shock. Of those, 992 weighted adult patient visits included an ECMO procedure yielding a rate of 0.1 per 1000 ED visits for cardiogenic shock.

The mean age of the study population was 50.8 years $(95 \% \mathrm{CI} 48.8-52.7)$. Patients were more commonly males (66.3\%; 95\%CI 60.3-71.8). Visits were equally distributed across all four seasons and were mainly during the weekday (Monday through Friday) $(70.6 \%, n=700)$. Over half of visits were to large metropolitan hospitals (fringe 39.4\%, $n=389$ and central 29.1\%, $n=287)$. Private insurance $(47.8 \%, n=$ 472) as well as Medicare and Medicaid $(43.6 \%, n=$ 430) were the most common primary expected payer types. (Table 1).

All patients had diseases of the circulatory system, and most patients had diseases of the respiratory system $(82.7 \%, n=820)$ as well as endocrine, nutritional, and metabolic diseases/immunity disorders $(80.1 \%, n=795)$ (Table 2). Few patients had injury diagnosis reported on record $(14.2 \%, n=141)$. The most frequent injury reported was suffocation injury $(1.9 \%, n=19)$ followed by falling injury $(1.5 \%, n=15)$. Only $5.3 \%(n=52)$ had increased injury severity defined by an ISS of 9 or greater. The mean for total charges (both ED and inpatient services) was $\$ 589,610.5$ (95\% CI 512,270.0 - 666,950.9). The mean hospital length of stay was 21.8 days (95\% CI 19.0-24.6).

In addition to ECMO, patients with cardiogenic shock underwent different types of procedures (Table 3). By procedure class, all patients had major therapeutic procedures on record since ECMO procedure is categorized as major therapeutic. Most patients $(89.1 \%, n=884)$ also had minor therapeutic procedures. The most common procedure other than ECMO was respiratory intubation and mechanical ventilation $(56.7 \%, n=562)$.

For Patients who underwent ECMO, there were significant differences between those who survived to 
Table 1 Characteristics of Study Population

\begin{tabular}{|c|c|c|c|}
\hline Continuous Variables & Range & Median (IQR) & Mean $(95 \% \mathrm{Cl})$ \\
\hline Age (years) & $18-90$ & $54(23)$ & $\begin{array}{l}50.8 \\
(48.8-52.7)\end{array}$ \\
\hline \multicolumn{2}{|c|}{ Categorical Variables } & Count $(N=992)$ & Percent (95\% CI) \\
\hline \multicolumn{2}{|c|}{ Gender (male) } & 658 & $66.3(60.3-71.8)$ \\
\hline \multicolumn{4}{|c|}{ Median household income ${ }^{a}$} \\
\hline \multicolumn{2}{|l|}{$\$ 1-\$ 37,999$} & 126 & $13.2(9.8-17.6)$ \\
\hline \multicolumn{2}{|l|}{$\$ 38,000-\$ 47,999$} & 238 & $25.1(19.9-31.0)$ \\
\hline \multicolumn{2}{|l|}{$\$ 48,000-\$ 63,999$} & 238 & $25.0(20.2-30.7)$ \\
\hline \multicolumn{2}{|l|}{$\$ 64,000$ or more } & 348 & $36.7(31.1-42.6)$ \\
\hline \multicolumn{4}{|l|}{ Season of admission } \\
\hline \multicolumn{2}{|l|}{ Winter } & 223 & $23.2(18.3-29.0)$ \\
\hline \multicolumn{2}{|l|}{ Spring } & 244 & $25.4(20.5-31.0)$ \\
\hline \multicolumn{2}{|l|}{ Summer } & 259 & $27.0(21.8-33.0)$ \\
\hline \multicolumn{2}{|l|}{ Autumn } & 234 & $24.3(19.5-29.9)$ \\
\hline \multicolumn{4}{|l|}{ Admission day } \\
\hline \multicolumn{2}{|l|}{ Monday - Friday } & 700 & $70.6(64.7-75.8)$ \\
\hline \multicolumn{2}{|l|}{ Saturday - Sunday } & 292 & $29.4(24.2-35.3)$ \\
\hline \multicolumn{4}{|l|}{ Patient location ${ }^{\mathrm{b}}$} \\
\hline \multicolumn{2}{|c|}{ Large central metropolitan } & 287 & $29.1(24.4-34.3)$ \\
\hline \multicolumn{2}{|c|}{ Large fringe metropolitan } & 389 & $39.4(34.5-44.5)$ \\
\hline \multicolumn{2}{|l|}{ Medium metropolitan } & 147 & $14.9(11.5-19.0)$ \\
\hline \multicolumn{2}{|l|}{ Small metropolitan } & 66 & $6.6(4.1-10.7)$ \\
\hline \multicolumn{2}{|l|}{ Micropolitan } & 51 & $5.1(3.2-8.1)$ \\
\hline \multicolumn{2}{|c|}{ Not metropolitan or micropolitan } & 48 & $4.9(3.0-7.9)$ \\
\hline \multicolumn{4}{|l|}{ Primary expected payer } \\
\hline \multicolumn{2}{|l|}{ Private insurance } & 472 & $47.8(41.6-54.1)$ \\
\hline \multicolumn{2}{|l|}{ Medicare \& Medicaid } & 430 & $43.6(37.3-50.1)$ \\
\hline \multicolumn{2}{|l|}{ Self-pay } & 60 & $6.1(3.8-9.7)$ \\
\hline \multicolumn{2}{|l|}{ Other } & 25 & $2.5(1.1-5.5)$ \\
\hline
\end{tabular}

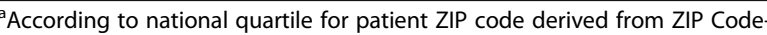
demographic data obtained from Claritas

${ }^{\mathrm{b}}$ According to National Center for Health Statistics (NCHS) Urban-rural code

hospital discharge and those who did not. Table 4 lists only the statistically significant variables between the two groups and which included age, season of admission, presence of certain chronic conditions and certain procedures, whether injury was reported, total charges, and length of stay (LOS). Those who survived were slightly younger than those who did not (49.5 vs 52.1 , years respectively $p=0.009)$ and had significantly higher total hospital charges for services as well as total length of stay.

Table 5 shows the variables associated with mortality in ECMO patients. Having diseases of either the respiratory system $(\mathrm{OR}=3.83,95 \% \mathrm{CI} 1.76-8.31)$ or genitourinary system $(\mathrm{OR}=4.97,95 \% \mathrm{CI} 2.39-10.33)$ as well as undergoing an echocardiogram $(\mathrm{OR}=4.63$,
95\%CI 1.300-16.504) were significantly associated with increased mortality. Higher mortality was also associated with visits during all seasons when compared to autumn.

Conversely, having a chronic disease of injury and poisoning ( $\mathrm{OR}=0.382$, 95\%CI 0.191-0.765), undergoing other operating room procedures on vessels other than head and neck ( $\mathrm{OR}=0.49,95 \% \mathrm{CI} 0.24-1.00)$, as well as increasing total charges (OR $=0.99395 \%$ CI $0.988-0.999)$ were associated with decreased mortality.

\section{Discussion}

ECMO use is increasing in adult patients with cardiogenic shock, but few studies that describe ECMO use or associations with mortality in this population are available. This study is the first to use the largest US ED database, NEDS, to describe socio-demographic, clinical, and hospital characteristics for patients with cardiogenic shock who underwent ECMO.

This study also described patterns of ECMO use and outcomes of patients with cardiogenic shock. ECMO was used in 0.1 per $1000 \mathrm{ED} /$ hospital visits with cardiogenic shock in 2013. Survival to hospital discharge was $51 \%$. This finding is consistent with survival rates from previous studies that range from 20 to $50 \%$ [1-10].

The mean age of patients who presented to US EDs with cardiogenic shock and who underwent ECMO was 50.8 years (95\%CI 48.4-52.7). Previous studies have shown similar characteristics [12, 24]. Maxwell et al. examined national ECMO use between the years 1998 to 2009 and found an overall mean age of $53.9 \pm 0.4$ years and a mean age of $48.9 \pm 0.8$ years among those with cardiogenic shock specifically [12]. Schmidt et al., on the other hand, analyzed ECMO use only for refractory cardiogenic shock between the years of 2003 and 2013 and found a mean age of 54 years (range 39-64) [24].

ECMO use as expected was mostly in large metropolitan hospitals. ECMO is considered a complex procedure and is fraught with complications such as stroke, neurologic complications, lower extremity ischemia, fasciotomy or compartment syndrome, amputation, acute kidney injury, renal replacement therapy, significant infection, major or significant bleeding and re-thoracotomy for bleeding or tamponade $[14,18]$. Thus, it is usually reserved for when conventional treatments have failed and is usually undertaken in larger specialized centers.

Seasonal variation in mortality among patients presenting with cardiogenic shock and undergoing ECMO procedure was also identified in this study. The association of seasonal patterns on both hospital admission and mortality has been previously examined and described among patients with cardiovascular disease. Previous studies have reported increased adverse effects (hospital admission and mortality) during colder months 
Table 2 Chronic Conditions, Injuries, and Outcomes of Sample Patients

\begin{tabular}{|c|c|c|c|c|}
\hline Categorical Variables & & & Count $(N=992)$ & Percent $(95 \% \mathrm{Cl})$ \\
\hline \multicolumn{5}{|l|}{ Chronic conditions body system indicator } \\
\hline Circulatory system & & & 992 & 100 \\
\hline Respiratory system & & & 820 & $82.7(77.5-86.9)$ \\
\hline Endocrine/nutritional/metabolic/immunity & & & 795 & $80.1(74.7-84.6)$ \\
\hline Symptoms, signs, and ill-defined conditions & & & 779 & $78.5(73.1-83.1)$ \\
\hline Genitourinary system & & & 724 & $72.9(67.1-78.1)$ \\
\hline Blood and blood-forming organs & & & 636 & $64.1(58.0-69.7)$ \\
\hline Injury and poisoning & & & 617 & $62.2(56.3-67.7)$ \\
\hline Digestive system & & & 414 & $41.8(35.8-47.9)$ \\
\hline Infectious and parasitic disease & & & 393 & $39.7(33.7-45.9)$ \\
\hline Health status/contact with health services factors & & & 383 & $38.6(33.1-44.4)$ \\
\hline Nervous system and sense organs & & & 313 & $31.5(26.1-37.5)$ \\
\hline Mental disorders & & & 186 & $18.8(14.3-24.2)$ \\
\hline \multicolumn{5}{|l|}{ Injury diagnosis reported on record } \\
\hline No injury diagnoses reported & & & 851 & $85.8(80.8-89.7)$ \\
\hline Injury is reported & & & 141 & $14.2(10.3-19.2)$ \\
\hline \multicolumn{5}{|l|}{ Injuries Specified by the NEDS Database } \\
\hline Injury by suffocation & & & 19 & $1.9(0.8-4.4)$ \\
\hline Injury by falling & & & 15 & $1.5(0.5-4.1)$ \\
\hline \multicolumn{5}{|l|}{ More than one injury diagnosis } \\
\hline One or no injury diagnosis reported & & & 938 & $94.5(90.9-96.7)$ \\
\hline More than one injury diagnosis & & & 54 & $5.5(3.3-9.1)$ \\
\hline \multicolumn{5}{|l|}{ Unintentional injury indicated } \\
\hline Intention not specified & & & 924 & $93.1(89.2-95.6)$ \\
\hline Unintentional injury & & & 68 & $6.9(4.4-10.8)$ \\
\hline Injury severity score & & & & $90.3(85.9-93.5)$ \\
\hline No injury severity score & & & 896 & $4.4(2.4-7.8)$ \\
\hline $1-8$ & & & 44 & $5.3(3.0-9.0)$ \\
\hline $9-75$ & & & 52 & \\
\hline \multicolumn{5}{|l|}{ Disposition of patient } \\
\hline Admitted to same hospital & & & 992 & 100 \\
\hline Survival to discharge & & & 506 & $51.0(44.8-57.1)$ \\
\hline Died in the ED/hospital & & & 486 & $49.0(42.9-55.2)$ \\
\hline Continuous Variables & Frequency & Range & Median (IQR) & Mean $(95 \% \mathrm{Cl})$ \\
\hline Total charges ${ }^{\mathrm{b}}$ (USD\$) & 988 & $3773-4,292,990$ & $409,138(468,598)$ & $589,610.5(512,270.0-666,950.9)$ \\
\hline Length of stay (days) & 992 & $0-131$ & $16(24)$ & $21.8(19.0-24.7)$ \\
\hline
\end{tabular}

${ }^{\mathrm{a}}$ Assigned by ICPIC Stata program

${ }^{\text {b}}$ Total charges are for accumulated ED and Inpatient services

(up to $10-20 \%$ increased mortality) [25-27]. Similarly, our study shows that the winter season was associated with the highest mortality (OR: 8.85; 95\%CI: 3.3923.11). Reasons for these seasonal variations though not directly identified in our study are multiple and complex, involving both physiologic and behavioral causes. Previously identified causes include sudden cold acclimatization, change in dietary patters, change in physical activity, changes in mental health, vitamin D deficiency, increased air pollution, and increased incidence of infectious disease [26].

This study also identified variables associated with mortality in patients with cardiogenic shock requiring ECMO. In addition to previously described associated 
Table 3 Extracorporeal Membrane Oxygenation Among Cardiogenic Shock: Procedures

\begin{tabular}{|c|c|c|}
\hline Procedure class for inpatient & Count $(N=992)$ & Percent $(95 \% \mathrm{Cl})$ \\
\hline Minor diagnostic & 534 & $53.8(47.8-59.7)$ \\
\hline Minor therapeutic & 884 & $89.1(84.6-92.4)$ \\
\hline Major diagnostic & 62 & $6.2(3.8-10.1)$ \\
\hline Major therapeutic & 992 & 100 \\
\hline Specific procedures using CCS codes & Count $(N=992)$ & Percent $(95 \% \mathrm{Cl})$ \\
\hline \multicolumn{3}{|l|}{ Circulator system procedures } \\
\hline Extracorporeal circulation auxiliary to open heart procedures ${ }^{\mathrm{a}}$ & 992 & 100 \\
\hline Other operating room heart procedures ${ }^{b}$ & 510 & $51.4(45.3-57.5)$ \\
\hline Diagnostic cardiac catheterization; coronary arteriography & 231 & $23.3(18.6-28.9)$ \\
\hline Conversion of cardiac rhythm & 183 & $18.4(14.4-23.3)$ \\
\hline Heart valve procedures & 179 & $18.1(13.9-23.1)$ \\
\hline Coronary artery bypass graft (CABG) & 150 & $15.1(11.5-19.6)$ \\
\hline Other non-operating room therapeutic cardiovascular procedures & 123 & $12.4(9.0-16.9)$ \\
\hline Percutaneous transluminal coronary angioplasty (PTCA) & 113 & $11.4(8.1-15.8)$ \\
\hline Echocardiogram & 107 & $10.8(7.6-15.3)$ \\
\hline Swan-Ganz catheterization for monitoring & 102 & $10.2(7.2-14.4)$ \\
\hline Blood transfusion & 220 & $22.2(17.9-27.2)$ \\
\hline \multicolumn{3}{|l|}{ Respiratory system procedures } \\
\hline Respiratory intubation and mechanical ventilation & 562 & $56.7(50.5-62.7)$ \\
\hline Other operating room procedures on respiratory system and mediastinum & 182 & $18.4(14.0-23.7)$ \\
\hline Diagnostic bronchoscopy and biopsy of bronchus & 135 & $13.6(10.0-18.3)$ \\
\hline Tracheostomy; temporary and permanent & 111 & $11.2(7.8-15.9)$ \\
\hline \multicolumn{3}{|l|}{ Other procedures } \\
\hline Other operating room procedures ${ }^{b}$ & 365 & $36.8(31.1-42.9)$ \\
\hline Other vascular catheterization; not heart & 330 & $33.3(27.8-39.3)$ \\
\hline Other therapeutic procedures ${ }^{c}$ & 207 & $20.9(16.5-26.1)$ \\
\hline
\end{tabular}

${ }^{a}$ This CCS procedure code also includes ICD-9 procedure code 39.65 for ECMO procedures

${ }^{b}$ Examples include operations on valves and septa of the heart, heart vessels, and the heart and pericardium

'Specifically procedures on vessels other than head/neck

${ }^{\mathrm{d}}$ Nervous, ophthalmic, gastrointestinal procedures not otherwise specified

clinical variables, the study examined different socioeconomic and system level factors that might be affecting mortality in this population. Patients with specific chronic conditions such as diseases of the respiratory system or the genitourinary system were more likely to die. This was expected given that patients with multiple organ dysfunction syndrome require ventilator support or dialysis and are more likely to die. These findings are similar to previous studies where pre-ECMO predictive survival score (SAVE-score) in patients with refractory cardiogenic shock identified chronic renal failure as risk factor associated with mortality [24].

The study also examined the costs and impact associated with ECMO use. The mean total charges for cardiogenic shock visits with ECMO procedure was $\$ 589,610.5$ (95\%CI $\$ 512,270.0 \quad-\$ 666,950.9)$ per admission. This mean is more than 10 times the national mean cost of patients with cardiogenic shock post ST-Elevation Myocardial Infarction in 2010 $(\$ 45,625)$ [28]. The mean length of stay for the study population was 21.8 days $(95 \% \mathrm{CI} 19.0-24.7)$. Both the mean cost and mean length of stay are higher than what Maxwell et al. previously reported on resource use trends in ECMO between 1998 and 2009 where the mean total hospital charges was $\$ 344,009$ $\pm \$ 30,707$ per admission and the mean length of stay was $18.3 \pm 1.3$ days [12]. Resources utilization with ECMO seem to be increasing without an associated increase in survival benefit. Future research is therefore needed to document trends in survival and the impact of ECMO use on outcomes of patients suffering from cardiogenic shock and from other conditions. ECMO is just one of several mechanical assist 
Table 4 Comparison of Study Groups Stratified by Outcome (Mortality)

\begin{tabular}{|c|c|c|c|c|c|}
\hline \multirow[b]{2}{*}{ Categorical Variables $^{a}$} & \multicolumn{2}{|c|}{$\begin{array}{l}\text { Survival to Discharge } \\
(N=506)\end{array}$} & \multicolumn{3}{|c|}{$\begin{array}{l}\text { Mortality } \\
(N=486)\end{array}$} \\
\hline & Count & Percent $(95 \% \mathrm{Cl})$ & Count & Percent $(95 \% \mathrm{Cl})$ & $p$-value \\
\hline \multicolumn{6}{|l|}{ Season of admission } \\
\hline Winter & 85 & $17.4(11.7-25.2)$ & 138 & $29.2(21.8-37.8)$ & \multirow[t]{4}{*}{0.006} \\
\hline Spring & 104 & $21.3(15.0-29.1)$ & 140 & $29.7(22.2-38.5)$ & \\
\hline Summer & 140 & $28.7(21.3-37.5)$ & 119 & $25.2(18.2-34.0)$ & \\
\hline Autumn & 159 & $32.6(25.6-40.3)$ & 75 & $15.9(10.3-23.7)$ & \\
\hline Chronic conditions & 506 & 100 & 487 & 100 & \\
\hline Respiratory system & 389 & $76.9(69.1-83.2)$ & 431 & $88.6(81.4-93.3)$ & 0.014 \\
\hline Injury and poisoning & 375 & $74.2(65.9-81.0)$ & 242 & $49.7(41.1-58.3)$ & $<0.001$ \\
\hline Genitourinary system & 305 & $60.4(51.7-68.4)$ & 419 & $86.0(79.6-90.7)$ & $<0.001$ \\
\hline Digestive system & 178 & $35.3(27.5-43.9)$ & 236 & $48.5(39.8-57.3)$ & 0.034 \\
\hline Nervous system \& sense organs & 127 & $25.1(18.4-33.4)$ & 186 & $38.2(30.1-46.9)$ & 0.025 \\
\hline \multicolumn{6}{|l|}{ Injury diagnosis } \\
\hline No injury diagnoses & 392 & $77.7(69.3-84.3)$ & 459 & $94.3(88.7-97.2)$ & \multirow[t]{2}{*}{$<0.001$} \\
\hline Injury is reported & 113 & $22.3(15.7-30.7)$ & 28 & $5.7(2.8-11.3)$ & \\
\hline \multicolumn{6}{|l|}{ Procedures } \\
\hline Other operating room procedures ${ }^{b}$ & 225 & $44.5(36.0-53.3)$ & 140 & $28.8(21.4-37.6)$ & 0.012 \\
\hline Tracheostomy $^{c}$ & 82 & $16.1(10.5-23.9)$ & 30 & $6.1(3.0-12.1)$ & 0.015 \\
\hline Echocardiogram & 36 & $7.1(3.8-12.9)$ & 71 & $14.7(9.5-22.0)$ & 0.05 \\
\hline Continuous Variables $^{\mathrm{d}}$ & Count & Mean $(95 \% \mathrm{Cl})$ & Count & Mean $(95 \% \mathrm{Cl})$ & $p$-value \\
\hline Age (years) & 506 & $49.5(46.8-52.1)$ & 487 & $52.1(49.3-54.9)$ & 0.009 \\
\hline Total charges ${ }^{\mathrm{e}}$ (USD) & 501 & 695,089.0 (560,971.1-829,206.8) & 487 & $480,927.5(398,015.8-563,839.2)$ & $<0.001$ \\
\hline Length of stay (days) & 506 & $28.8(24.4-33.1)$ & 487 & $14.6(11.5-17.6)$ & $<0.001$ \\
\hline
\end{tabular}

devices used in cardiogenic shock. Other devices include intra-aortic balloon pumps (IABP) and LV assist devices (LVADs). ECMO however, is the only intervention that compensates for both the right and left heart function as well as lung function. As such, ECMO decreases requirements for catecholamine, vasodilator, and mechanical ventilation in the treatment of cardiogenic shock and reduces the complications that are usually associated with these treatment modalities $[18,29]$. ECMO use therefore holds promise for use in selected cardiogenic shock patients and further prospective studies are recommended.

The limitations of this study are directly related to structural features of the NEDS database. First, ICD-9 $\mathrm{CM}$ codes do not differentiate between VA or VV ECMO. This may be resolved with future use of ICD-10 CM codes. Second, information on the duration of ECMO use or timing of initiation is not available and costs are allocated to the whole hospital admission and not to a specific resource. Other limitations are related to the retrospective nature of the study. The quality and quantity of the data depends on the knowledge and experience of the coder, the completeness and accuracy of the patient record, and the state requirements. The study findings portray however trends in ECMO use for cardiogenic shock from a large sample from US based hospitals and can be generalized to other hospitals from similar settings.

\section{Conclusion}

Mortality in adult patients with cardiogenic shock remains high despite ECMO use. Season of admission (other than Fall) and presence of specific comorbidities (Respiratory and genitourinary diseases) are associated with increased mortality in this population. Familiarity with patients' characteristics and variables associated with mortality after ECMO use is important to improve outcomes further in cardiogenic 
Table 5 Mortality with ECMO use in Cardiogenic Shock

\begin{tabular}{|c|c|c|c|}
\hline & Odds Ratio & $95 \% \mathrm{Cl}$ & $p$-value \\
\hline$\overline{\mathrm{CCl}^{\mathrm{b}} \text { - Nervous system and sense organs diseases }}$ & 1.22 & $0.64-2.32$ & 0.541 \\
\hline $\mathrm{CCl}$ - Respiratory system diseases & 3.83 & $1.76-8.31$ & 0.001 \\
\hline CCl - Digestive system diseases & 1.72 & $0.82-3.61$ & 0.150 \\
\hline $\mathrm{CCl}$ - Genitourinary system diseases & 4.97 & $2.39-10.33$ & $<0.001$ \\
\hline $\mathrm{CCl}$ - Injury and poisoning & 0.47 & $0.24-0.94$ & 0.032 \\
\hline Injury diagnosis reported & 0.45 & $0.15-1.36$ & 0.156 \\
\hline Tracheostomy; temporary and permanent & 0.46 & $0.14-1.48$ & 0.190 \\
\hline Other operating room procedures ${ }^{c}$ & 0.49 & $0.24-1.00$ & 0.048 \\
\hline Echocardiogram & 4.63 & $1.30-16.50$ & 0.018 \\
\hline \multicolumn{4}{|l|}{ Season of admission (Autumn) } \\
\hline Winter & 8.85 & 3.39-23.11 & $<0.001$ \\
\hline Spring & 5.44 & $2.16-13.73$ & $<0.001$ \\
\hline Summer & 4.02 & $1.54-10.46$ & 0.005 \\
\hline Age (1 year) & 1.01 & $1.00-1.04$ & 0.239 \\
\hline Length of Stay (1 day) & 0.94 & $0.90-0.98$ & 0.003 \\
\hline Total charges $^{\mathrm{d}}$ (per $\left.\$ 10,000\right)$ & 1.01 & $1.00-1.02$ & 0.069 \\
\hline
\end{tabular}

${ }^{a}$ Variables included in the model are: significant chronic conditions and procedures found at the bivariate level, injury diagnosis, season of admission, age, and total charges

${ }^{\mathrm{b}} \mathrm{CCl}$ denotes body system categories affected by chronic conditions

'Specifically procedures on vessels other than head and neck

${ }^{\mathrm{d}}$ Total charges are for accumulated ED and Inpatient services

shock. With rising costs and resources utilization, future research should focus on the impact of ECMO use on survival and on outcomes of patients with critical illnesses including but not limited to cardiogenic shock.

\section{Additional File}

Additional File 1: A list of Equivalent ICD-9 CM codes and variable classification. (DOCX $106 \mathrm{~kb}$ )

\section{Abbreviations \\ AHRQ: Agency for Healthcare Research and Quality; CCS: Clinical Classifications Software; Cl: confidence intervals; CPR: Cardiopulmonary Resuscitation; \\ ECLS: extracorporeal life support; ECMO: Extracorporeal membrane oxygenation; ED: emergency department; ELSORIR: Extracorporeal Life Support Organization Registry International Report; HCUP: Healthcare Cost and Utilization Project; IABP: include intra-aortic balloon pumps; ICD: International Classification of Diseases; IRB: Institutional Review Board; LOS: length of stay; LVADs: LV assist devices; NEDS: Nationwide Emergency Department Sample; VA: veno-arterial; W: veno-venous}

\section{Funding}

There are no sources of funding for the research reported.

\section{Availability of data and materials}

The data that support the findings of this study are available from HCUP but restrictions apply to the availability of these data, which were used under license for the current study, and so are not publicly available, Data are however available from the authors upon reasonable request and with permission of HCUP. More information can be accessed via: www.hcup-us.ahrq.gov/nedsoverview.jsp.

\section{Authors' contributions}

ME provided substantial involvement in the conception, design, and execution of the manuscript as well as reviewing and revising the manuscript for its credible content. RE provided substantial involvement in the design, and execution of the manuscript as well as drafting and revising the manuscript. RB provided substantial involvement in design and reviewing the manuscript as well as analysis of data. All authors read and approved the final manuscript.

\section{Ethics approval and consent to participate}

An exemption for the use of this de-identified dataset was obtained from the institutional review board (IRB) office at the American University of Beirut. This database is defined as limited data set under the HIPAA Privacy Rule and as such is de-identified prior to use and is waived from consent.

\section{Consent for publication}

Not applicable.

\section{Competing interests}

The authors declare that they have no competing interests.

\section{Publisher's Note}

Springer Nature remains neutral with regard to jurisdictional claims in published maps and institutional affiliations.

Received: 3 December 2017 Accepted: 21 June 2018

Published online: 04 July 2018

\section{References}

1. Massetti M, Tasle M, Le Page O, Deredec R, Babatasi G, Buklas D, Thuaudet S, Charbonneau P, Hamon M, Grollier G, et al. Back from irreversibility: extracorporeal life support for prolonged cardiac arrest. Ann Thorac Surg. 2005;79(1):178-83. discussion 183-174

2. Kelly RB, Porter PA, Meier AH, Myers JL, Thomas NJ. Duration of cardiopulmonary resuscitation before extracorporeal rescue: how long is not long enough? ASAIO J (Am Soc for Artif Inter Organs : 1992). 2005;51(5): 665-7. 
3. Shin TG, Choi JH, Jo IJ, Sim MS, Song HG, Jeong YK, Song YB, Hahn JY, Choi $\mathrm{SH}$, Gwon $\mathrm{HC}$, et al. Extracorporeal cardiopulmonary resuscitation in patients with inhospital cardiac arrest: a comparison with conventional cardiopulmonary resuscitation. Crit Care Med. 2011;39(1):1-7.

4. Thiagarajan RR, Barbaro RP, Rycus PT, McMullan DM, Conrad SA, Fortenberry JD, Paden ML. Extracorporeal life support organization registry international report 2016. ASAIO J (Am Soc for Artif Inter Organs : 1992). 2017;63(1):60-7.

5. Younger JG, Schreiner RJ, Swaniker F, Hirschl RB, Chapman RA, Bartlett RH. Extracorporeal resuscitation of cardiac arrest. Acad Emerg Med Off J Soc Acad Emerg Med. 1999;6(7):700-7.

6. Combes A, Leprince P, Luyt CE, Bonnet N, Trouillet JL, Leger P, Pavie A, Chastre J. Outcomes and long-term quality-of-life of patients supported by extracorporeal membrane oxygenation for refractory cardiogenic shock. Crit Care Med. 2008;36(5):1404-11.

7. Smedira NG, Blackstone EH. Postcardiotomy mechanical support: risk factors and outcomes. Ann Thorac Surg. 2001;71(3 Suppl):S60-6. discussion S82-65

8. Bednarczyk JM, White CW, Ducas RA, Golian M, Nepomuceno R, Hiebert B, Bueddefeld D, Manji RA, Singal RK, Hussain F, et al. Resuscitative extracorporeal membrane oxygenation for in hospital cardiac arrest: a Canadian observational experience. Resuscitation. 2014;85(12):1713-9.

9. Pagani FD, Aaronson KD, Swaniker F, Bartlett RH. The use of extracorporeal life support in adult patients with primary cardiac failure as a bridge to implantable left ventricular assist device. Ann Thorac Surg. 2001;71(3 Suppl): S77-81. discussion S82-75

10. Kagawa E, Dote K, Kato M, Sasaki S, Nakano Y, Kajikawa M, Higashi A, Itakura K, Sera A, Inoue I, et al. Should we emergently revascularize occluded coronaries for cardiac arrest?: rapid-response extracorporeal membrane oxygenation and intra-arrest percutaneous coronary intervention. Circulation. 2012;126(13):1605-13.

11. Squiers JJ, Lima B, DiMaio JM. Contemporary extracorporeal membrane oxygenation therapy in adults: fundamental principles and systematic review of the evidence. J Thorac Cardiovasc Surg. 2016;152(1):20-32.

12. Maxwell BG, Powers AJ, Sheikh AY, Lee PHU, Lobato RL, Wong JK. Resource use trends in extracorporeal membrane oxygenation in adults: an analysis of the Nationwide inpatient sample 1998-2009. J Thorac Cardiovasc Surg. 2014;148(2):416-21. e411

13. Lazzeri C, Bernardo P, Sori A, Innocenti L, Stefano P, Peris A, Gensini GF, Valente S. Venous-arterial extracorporeal membrane oxygenation for refractory cardiac arrest: a clinical challenge. Europ Heart J Acute Cardiovasc Care. 2013;2(2):118-26.

14. Cheng R, Hachamovitch R, Kittleson M, Patel J, Arabia F, Moriguchi J, Esmailian F, Azarbal B. Complications of extracorporeal membrane oxygenation for treatment of cardiogenic shock and cardiac arrest: a metaanalysis of 1,866 adult patients. Ann Thorac Surg. 2014;97(2):610-6.

15. Reyentovich A, Barghash MH, Hochman JS. Management of refractory cardiogenic shock. Nat Rev Cardiol. 2016;13(8):481-92.

16. Sheu J. Early extracorporeal membrane oxygenator-assisted primary percutaneous coronary intervention improved 30-day clinical outcomes in patients with ST-segment elevation myocardial infarction complicated with profound cardiogenic shock. Crit Care Med. 2010;38(9):1810-7.

17. Chen YS, Lin JW, Yu HY, Ko WJ, Jerng JS, Chang WT, Chen WJ, Huang SC, Chi $\mathrm{NH}$, Wang $\mathrm{CH}$, et al. Cardiopulmonary resuscitation with assisted extracorporeal life-support versus conventional cardiopulmonary resuscitation in adults with in-hospital cardiac arrest: an observational study and propensity analysis. Lancet. 2008;372(9638):554-61.

18. Napp LC, Kühn C, Bauersachs J. ECMO in cardiac arrest and cardiogenic shock. Herz. 2017;42(1):27-44.

19. HCUP Nationwide Emergency Department Sample (NEDS). In.: Healthcare Cost and Utilization Project (HCUP); 2013.

20. Barrett M, Lopez-Gonzalez L, Coffey R, Levit K. Population Denominator Data for Use with the HCUP Databases (Updated with 2013 Population Data). 2014. HCUP Methods Series Report \# 2014-02 ONLINE. August 18, 2014. U.S. Agency for Healthcare Research and Quality. Available: http://www.hcup-us. ahrq.gov/reports/methods/methods.jsp. Accessed 10 Oct 2017.

21. Sasser SM, Hunt RC, Faul M, Sugerman D, Pearson WS, Dulski T, Wald MM Jurkovich GJ, Newgard CD, Lerner EB. Guidelines for field triage of injured patients: recommendations of the National Expert Panel on field triage, 2011. MMWR Recommendations and reports. Morb Mortal Wkly Rep Recomm Rep / Ctr Dis Control. 2012;61(Rr-1):1-20.

22. Palmer C. Major trauma and the injury severity score - where should we set the bar? Ann Proc / Assoc for the Adv of Automotive Med. 2007:51:13-29.

23. HCUPnet [https://hcupnet.ahrq.gov/\#setup].
24. Schmidt M, Burrell A, Roberts L, Bailey M, Sheldrake J, Rycus PT, Hodgson C, Scheinkestel C, Cooper DJ, Thiagarajan RR, et al. Predicting survival after ECMO for refractory cardiogenic shock: the survival after veno-arterial-ECMO (SAVE)-score. Eur Heart J. 2015;36(33):2246-56.

25. Spencer FA, Goldberg RJ, Becker RC, Gore JM. Seasonal distribution of acute myocardial infarction in the second National Registry of myocardial infarction. J Am Coll Cardiol. 1998;31(6):1226-33.

26. Stewart S, Keates AK, Redfern A, McMurray JJ. Seasonal variations in cardiovascular disease. Nat Rev Cardiol. 2017;14(11):654.

27. Turin TC, Kita Y, Rumana N, Nakamura Y, Takashima N, Miura K, Ueshima H. Increased risk of acute myocardial infarction during colder periods is independent of the conventional cardiovascular risk factors: Takashima AMI Registry, Japan. CVD Prev Cont. 2011;6(3):109-11.

28. Kolte D, Khera S, Aronow WS, Mujib M, Palaniswamy C, Sule S, Jain D, Gotsis W, Ahmed A, Frishman WH, et al. Trends in incidence, management, and outcomes of cardiogenic shock complicating ST-elevation myocardial infarction in the United States. J Am Heart Assoc. 2014;3(1):e000590.

29. Shock C. Current concepts and improving outcomes. Hochman. Harmony R Reynolds and Judith S sl. Circulation. 2008;117(5):686-97.

\section{Ready to submit your research? Choose BMC and benefit from:}

- fast, convenient online submission

- thorough peer review by experienced researchers in your field

- rapid publication on acceptance

- support for research data, including large and complex data types

- gold Open Access which fosters wider collaboration and increased citations

- maximum visibility for your research: over $100 \mathrm{M}$ website views per year

At BMC, research is always in progress.

Learn more biomedcentral.com/submissions 